\title{
AVÓS QUE DETÊM A GUARDA JUDICIAL DOS NETOS: QUE LUGAR É ESSE?
}

\section{Cristina Maria de Souza Brito Dias Universidade Católica de Pernambuco}

\author{
Karlise Maranhão Lucena de Albuquerque \\ Judicial de Pernambuco na 1. Vara da Infância e Juventude
}

\begin{abstract}
Resumo
O objetivo geral desta pesquisa foi investigar, na perspectiva das avós, o lugar ocupado por elas nos contextos familiar e social, a partir do deferimento da guarda judicial de seus netos. Participaram cinco avós, de nível socioeconômico médio-baixo, que cuidam integralmente dos netos. Elas responderam a um questionário sociodemográfico e a uma entrevista. Esta foi analisada pela técnica da análise de conteúdo temática. Pode-se constatar que: 1) a solicitação da guarda foi uma consequência natural, uma vez que, em sua maioria, elas já cuidavam dos netos; 2) os motivos que as levaram a assumir os netos foram separação, encarceramento, negligência e morte dos genitores; 3) os ganhos obtidos com a guarda judicial foram a segurança de poder atender às necessidades dos netos, sem o risco de que eles lhes sejam retirados, e união na família; 4) todas se perceberam e são reconhecidas como mães dos netos.
\end{abstract}

Palavras-chave: guarda judicial; poder judiciário; avós guardiãs; netos.

\section{GRANDMOTHERS WHO HAVE JUDICIAL CUSTODY OF GRANDCHILDREN: WHAT PLACE IS THIS?}

\begin{abstract}
The general objective of this research was to investigate, from the perspective of the grandmothers, the place occupied by them in the family and social contexts, from the deferment of the judicial custody of their grandchildren. Five grandmothers, of medium-low socioeconomic status and fully caring for the grandchildren, participated. They answered a sociodemographic questionnaire and an interview. These were analyzed by the thematic content analysis technique. It can be verified that: 1) the request of the guard was a natural consequence, since, for the majority, they already took care of the grandchildren; 2) the motives that led them to assume the grandchildren were separation, incarceration, negligence and death of genitors 3) the gains obtained with judicial custody were the security of being able to attend the needs of grandchildren, without the risk that they would be taken away, and family union; 4) all perceive themselves and are recognized as mothers of the grandchildren.

Keywords: judicial custody; judicial power, guardian grandmothers, grandchildren.
\end{abstract}

\section{ABUELAS QUE DETIENEN LA GUARDIA JUDICIAL DE LOS NIETOS: ¿QUÉ LUGAR ES ÉSTE?}

\begin{abstract}
Resumen
El objetivo general de esta investigación fue investigar, en la perspectiva de las abuelas, el lugar ocupado por ellas en los contextos familiar y social, a partir de la aceptación de la custodia judicial de sus nietos. Participaron cinco abuelas, de nivel socioeconómico medio-bajo y que cuidan íntegramente a los nietos. Ellas respondieron a un cuestionario sociodemográfico ya una entrevista. Esta fue analizada por la técnica del análisis de contenido temático. Se puede constatar que: 1) la solicitud de la guardia fue una consecuencia natural, ya que, en su mayoría, ellas ya cuidaban de los nietos; 2) los motivos que las llevaron a asumir los nietos fueron separación, encarcelamiento, negligencia y muerte de genitores; 3) las ganancias obtenidas con la guardia judicial fueron la seguridad de poder atender a las necesidades de los nietos, sin el riesgo de que ellos sean retirados de ellas, y la unión de la familia; 4) todas se percibieron y son reconocidas como madres de los nietos.
\end{abstract}


Palabras clave: guardia judicial; poder judicial; abuelas guardianas; nietos.

\section{INTRODUÇÃO}

No Brasil é cada vez mais comum que avós se responsabilizem material e afetivamente pelos seus netos, seja por conta do desemprego e do acúmulo de dívidas, da gravidez na adolescência, separação ou migração dos pais, assim como do uso abusivo de drogas, até a morte dos mesmos, entre outros fatores. (Cardoso, 2011; Dias, Aguiar \& Hora, 2009; Schuler \& Dias, 2017; Peixoto \& Luz, 2007).

No decorrer dos anos de trabalho de uma das autoras como psicóloga jurídica na Primeira Vara da Infância e Juventude de Recife, no Núcleo Integrado de Assessoramento Psicossocial (NIAP), por meio da leitura inicial dos processos, observou-se que o perfil dos requerentes é predominantemente de avós que, de uma forma corriqueira, aparecem como autores das ações. Na maioria dos casos, elas desejam a regularização da convivência com os netos que, muitas vezes, já é estabelecida desde os primeiros dias de vida das crianças.

Destaca-se que a guarda é uma das modalidades de colocação em família substituta, elencadas na Lei 8069/90, conhecida como Estatuto da Criança e do Adolescente. Ela tem como finalidade inserir a criança ou adolescente em um lar substituto, que ofereça todas as condições necessárias para o seu bom desenvolvimento social e emocional, tais como suporte material, educação, saúde, valores morais, que não foram oferecidos pelos detentores naturais do poder familiar, ou seja, pai ou mãe.

Existe uma concepção de que os avós deveriam ficar na posição de apoiar e aconselhar os pais, quando solicitados, mantendo o equilíbrio entre dar afeto aos netos sem exagerar nos mimos e ajudar os filhos sem oprimi-los ou tirarIhes sua autoridade (Aratangy \& Posternack, 2005; Dias, 2015; Dolto, 1998). Contudo, o que tem se observado na prática é que muitos avós passam a assumir o papel parental junto aos seus netos, o que leva, na maioria das vezes, crianças/adolescentes a reconhecê-los como seus próprios pais, devido ao forte vínculo afetivo que é construído nesta relação.

Tornar-se avós guardiões, atualmente, é um fenômeno cada vez mais comum, sendo necessária a compreensão da realidade social das famílias que vivenciam esses casos, bem como a reflexão acerca de possibilidades de intervenção profissional nesse campo de estudo. De acordo com Pedro (2006), a guarda parcial ou temporária dos netos, por parte dos avós, passou a ser uma necessidade social.

Diante do exposto, esta pesquisa teve como objetivo geral investigar, na perspectiva das avós, o lugar ocupado por elas, nos contextos familiar e social, após o deferimento da guarda judicial de seus netos. 


\section{A família como sistema em interação com a Justiça}

A diversificação dos arranjos familiares marca este século de forma profunda. É crescente o número de divórcios e separações, surgindo organizações familiares diversas, tais como: casamentos sucessivos com parceiros distintos e filhos de diferentes uniões; casais com filhos ou parceiros isolados ou mesmo o casal vivendo com uma das famílias de origem; uniões de pessoas do mesmo sexo e casais homossexuais adotando filhos legalmente; mães ou pais sozinhos vivendo e cuidando de seus filhos; reproduções independentes passam a ser frequentes; avós cuidando de netos; domicílios formados por grupos de amigos que decidem morar juntos e outras várias formas de relações que nos colocam diante de novas organizações de família, diferenciando-se do clássico modelo nuclear (Osório, 2013; Walsh, 2016).

A presença de avós nas famílias e, até mesmo de bisavós, considerando a longevidade atual, é consequência de melhorias científicas, tecnológicas e econômicas. Isto é, as conquistas da ciência e dos diversos setores da economia na ampliação da qualidade de vida, bem como o acesso à informação, estão permitindo às pessoas viver mais e melhor, o que constitui um ganho para a sociedade.

As significativas transformações observadas nas famílias brasileiras, como o envelhecimento populacional que tem possibilitado sua verticalização, a participação das mulheres no mercado de trabalho e as novas configurações familiares contribuem para que, cada vez mais, as gerações de uma mesma família convivam por mais tempo. Nesse contexto, os mais velhos passam a se responsabilizar pelos mais novos, pois a mãe que antes estaria em casa cuidando de seus filhos, em geral, está na esfera pública, contribuindo com o seu salário para a renda familiar, por exemplo.

Neste trabalho, tomamos como referencial teórico o Pensamento Sistêmico, que diz: "um sistema é um todo integrado, cujas propriedades não podem ser reduzidas às propriedades das partes" (Vasconcellos, 2002, p. 200). Essa ideia implica que o todo é mais complexo do que a soma das suas partes, sendo que a interação entre as partes que constitui um sistema torna seus elementos interdependentes, "cada parte estará de tal forma relacionada com as demais, que a mudança em uma delas acarretará mudanças nas outras (Vasconcellos, 2002, p. 199). Entende-se que, para se ter conhecimento das partes, é necessário que haja a compreensão das relações entre elas.

A família, por ser um sistema aberto, realiza intercâmbios com os subsistemas internos e outros sistemas (escola, trabalho, comunidade). Minuchin (1999, p. 22) afirmou: "Uma família é um tipo especial de sistema, com estrutura, padrões e propriedades que organizam a estabilidade e a mudança. É também uma pequena sociedade humana, cujos membros têm contato direto, laços emocionais e uma história compartilhada". 
O sistema familiar não se restringe à família nuclear, mas inclui a família extensa ou ampliada. Sendo assim, a família ampliada está intrinsecamente ligada aos processos de mudanças pelos quais passa a família nuclear, como aos momentos de crise conjugal, divórcio, doenças, morte, entre outros, atuando os avós, por exemplo, como conselheiros dos filhos e rede de apoio aos netos (Walsh, 2016).

Levando em conta a família como um sistema aberto, interagindo com outros sistemas, é interessante pontuar a existência de uma ligação da família com o sistema judicial, já que este contexto é ponto chave deste trabalho, sendo neste ambiente que os avós formalizam sua responsabilidade legal perante seus netos. Assim, no sistema da Justiça, os membros das famílias, que anteriormente eram classificados como vítimas e algozes, passaram a ser considerados como pessoas em litígio, em disputa, mas em constante interação, sem que haja culpados ou inocentes, considerando que todos são corresponsáveis pelos problemas.

Nesse contexto, de acordo com Lima e Ribeiro (2008), as questões e os problemas envolvidos passaram a ser vistos como pertencentes à unidade familiar, considerando-se a singularidade da família. Ressalta-se que o Judiciário também pode ser visto como um sistema aberto e que qualquer decisão ou sentença definida pelo juiz vai implicar na vida não apenas de uma das partes, mas de todos os envolvidos no litígio. As soluções encontradas nunca afetarão uma parte de forma isolada, mas estarão sempre abrangendo todo o sistema envolvido na lide.

É nessa linha de pensamento que entendemos os sistemas familiar e jurídico como sistemas abertos, em constante transformação, onde a alteração em uma parte estará modificando o sistema como um todo. Os dois sistemas mantêm uma interdependência entre seus membros e entre eles mesmos, utilizando-se de recursos como a retroalimentação para preservarem sua organização interna.

Avós sempre auxiliaram nos cuidados com os netos, contudo, de algumas décadas para cá, tem-se notado o seu protagonismo cada vez maior nas famílias. Deixando de ser apenas avós, passaram a exercer as funções parentais e assim precisam regularizar esta situação para que os netos não fiquem desprotegidos perante a lei.

Chaves (2014) nomeou como avocentrismo a situação dos avós que são os protagonistas de suas famílias, quando assumem a responsabilidade, de forma espontânea ou outorgada, de cuidar dos netos, devido à incapacidade ou impossibilidade (temporária ou permanente) dos genitores no cuidado com os filhos.

O ciclo natural da vida nem sempre ocorre de forma linear. Ainda de acordo com Chaves (2014), as fases e etapas do desenvolvimento humano, como sair da casa dos pais, casar, ter filhos e netos, e, posteriormente, seus 
filhos e netos também constituírem as suas famílias tornou-se um modelo ideal, e não real, em nossa sociedade. Famílias se rompem, fases desse ciclo são alteradas, famílias são desfeitas e refeitas. E quando crianças e adolescentes são inseridos em contextos familiares de rupturas, os danos podem ser bem maiores. Por esta razão, há a necessidade da proteção integral e um olhar diferenciado a essas famílias, que precisam recorrer à ajuda do Estado. Este é o caso dos avós que precisam solicitar a guarda dos netos na Justiça para ter os direitos dos seus descendentes e os seus próprios garantidos.

Quando um (a) avô/avó assume a criação do neto, é estabelecida uma configuração familiar específica que merece ser vista com cautela, pois como pontuaram Dias e Costa (2006), cuidar dos netos é uma situação permeada de sentimentos ambivalentes, podendo eliciar alegria e prazer, mas também acarretar muitas tarefas físicas e emocionais que, para muitos avós, podem ser prejudiciais.

Dias, Fonseca, Silva e Muniz (2013) realizaram uma intervenção com 57 avós que criavam netos, em tempo integral ou parcial, e foram encontrados sentimentos de ansiedade, depressão e cansaço nas avós, bem como confusão de papel e preocupação com o futuro dos netos. Além disso, as avós também referiram a sobrecarga financeira, os conflitos com os filhos devido às divergências na educação das crianças e, às vezes, pela custódia legal dos netos. Além disso, algumas avós apontaram um decréscimo na qualidade da saúde física e emocional, interferência na vida social e familiar, cansaço e esgotamento emocional.

Dias e Schuler (2013) acrescentaram que cuidar dos netos pode gerar várias dificuldades para as avós, tais como: estresse, depressão, declínio da saúde, problemas econômicos, preocupações com a escolaridade e disciplina dos netos, confusão de papéis, uma vez que assumem a função de pais e de avós, ao mesmo tempo. Elas ainda podem desenvolver sentimentos de vergonha, perda, culpa e mágoa em relação aos filhos que as deixaram nesta situação.

Apesar disso, esses sentimentos mencionados parecem ser contrabalanceados quando constatamos que há avós que, muito embora diante das dificuldades vivenciadas, desenvolvem sentimentos genuínos ao tentarem ser melhores como avós do que como pais, auferindo prazer e satisfação ao oferecer os cuidados diários aos netos. Lopes, Neri e Park (2005) citaram o sentimento de renovação pessoal, oportunidade de ter companhia e gratificação por estarem provendo uma nova geração com cuidados e ensinamentos. Cardoso (2011) ainda acrescentou que a convivência entre avós e netos permite uma relação afetiva próxima que é benéfica para ambos.

Rocha (2017) realizou uma pesquisa referente aos processos de guarda existentes nas Varas de Família do estado de Pernambuco e encontrou várias motivações que levaram os avós a recorrerem à Justiça, visando garantir a proteção aos netos sob diversos aspectos. As motivações mais preponderantes e, 
por esta razão analisadas de forma mais detalhada pela pesquisadora, foram as motivações financeiras e afetivas.

Ainda de acordo com a pesquisadora, ela encontrou uma predominância do sexo feminino entre as avós que figuravam como parte processual nas ações judiciais e a faixa etária de maior recorrência foi 51-60 anos. Em sua análise, a pesquisadora destacou a existência de um maior número de casos de coabitação onde existiam avós, filhos e netos, vivendo na mesma residência, fato que difere dos achados desta pesquisa, em que os genitores são ausentes.

Vale ressaltar que essa pesquisa foi realizada na Vara da Infância, para onde são designados os processos de crianças que estão vivendo uma situação de vulnerabilidade social (maus tratos, negligência, abuso físico, sexual, psicológico, abandono ou ausência dos pais). Por esta razão, os processos da Vara da Infância de Pernambuco, diferentemente dos processos das Varas de Famílias do mesmo Estado, em sua maioria, não há coabitação dos avós, pais e netos, razão que inclusive impediria o deferimento da guarda aos avós, já que as crianças ou adolescentes precisam estar em um ambiente livre de sofrimento, tendo seus direitos preservados e garantidos.

Na Vara da Infância, observa-se a participação da família como rede de apoio ou de solidariedade familiar, de duas formas: 1) Devido ao desemprego, carência de habitação e creches, os pais deixam seus filhos sob os cuidados dos avós; 2) Situações, tais como uso de drogas, insuficiência financeira, negligência, violências, que impedem o exercício do poder familiar dos genitores, por violar a garantia de direitos das crianças e adolescentes.

Dito isto, entende-se que a participação dos avós nos cuidados dos netos existe tanto como uma cooperação espontânea, como não espontânea. A primeira, seria deixar os filhos sob os cuidados dos avós enquanto os pais trabalham para, ao final do dia, levarem as crianças para casa novamente. Nesse caso, não há coabitação, sendo um tipo de apoio verificado em famílias que não possuem condições de remunerar alguém para cuidar de seus filhos ou não há possibilidade de deixá-los em creches. O lugar simbólico do avô e/ou da avó é de corresponsabilidade temporária e os genitores exercem as suas funções maternas e paternas.

A segunda forma de cooperação, por outro lado, a não espontânea, acontece nas situações em que os avós se tornam integralmente provedores de suas famílias e, principalmente, cuidadores primários dos netos. Assim, as funções familiares são invertidas e até mesmo perdidas diante dessa nova realidade. Neste sentido, Vitale (2008, p. 94), pesquisando as relações intergeracionais na família e a figura dos avós na contemporaneidade, pontuou:

As mudanças dos laços familiares e a vulnerabilidade que atinge as famílias demandam novos papéis, novas exigências para essas figuras, personagens que ganham relevo não só na relação afetiva com os netos, mas também como auxiliares na socialização das 
crianças ou mesmo no seu sustento, mediante suas contribuições financeiras.

É nessa segunda situação que este trabalho está centrado: são avós cuidadores de netos, que por razão de os terem assumido integralmente precisaram se dirigir à Justiça, para regularizar a situação, e assim passaram a ter a guarda legal dos mesmos.

\section{MÉTODO}

\section{Participantes}

Participaram da pesquisa cinco avós, do sexo feminino, na faixa etária entre 42 e 64 anos, de nível socioeconômico médio-baixo, que fizeram a solicitação e obtiveram a guarda judicial dos netos. Vale ressaltar que não houve delimitação de sexo para os participantes, contudo, após a escolha da amostra, apenas avós do sexo feminino, estiveram disponíveis à participação nesta pesquisa.

\section{Instrumentos}

As participantes responderam a um questionário sociodemográfico (idade, estado civil, escolaridade, profissão, quantidade de netos, tempo de aquisição do termo de guarda, entre outros). Em seguida, foi realizada uma entrevista semidirigida, que possibilitou uma maior proximidade entre o pesquisador e o sujeito participante da pesquisa, sendo uma técnica muito utilizada no trabalho de campo, em pesquisas qualitativas. Foi elaborado um roteiro prévio, pelas próprias pesquisadoras, correspondendo aos objetivos da pesquisa, visando auxiliar na busca das informações sobre o problema de pesquisa.

\section{Procedimento de coleta}

O projeto foi submetido ao Comitê de Ética da Instituição e aprovado sob o número CAAE 61120316.7.0000.5206. Após esta etapa, foi dado início a uma análise dos documentos referentes aos autos dos processos das famílias, entre os anos de 2013 a 2015, visando analisar as petições iniciais e pareceres técnicos construídos pelos profissionais que trabalham no Núcleo NIAP, a fim de verificar a razão que originou o pedido da guarda judicial pelos avós.

A escolha dos anos 2013 a 2015 se deu em razão da finalização do trâmite do processo judicial, com o deferimento do Termo de Guarda aos requerentes, neste caso, as avós selecionadas. Os documentos analisados compreendem a petição inicial, formalizada por advogados particulares ou defensores públicos; o estudo de caso, elaborado pela equipe técnica do referido núcleo, com seus pareceres e laudos psicológicos e sociais. Foram selecionados 20 casos que diziam respeito ao processo de guarda e destes foram sorteados os cinco casos que constam desta pesquisa. As avós foram contatadas por telefone, 
cientificadas do objetivo da pesquisa e entrevistadas em sua própria casa. Elas assinaram o Termo de Consentimento Livre e Esclarecido e tiveram os nomes trocados para preservar sua identidade.

\section{Procedimento de análise dos dados}

As informações coletadas foram analisadas tendo como base a técnica da Análise de Conteúdo Temática. Para Minayo (2014), a primeira fase, a préanálise se refere à leitura flutuante, ou seja, o pesquisador deixa-se impregnar pelo conteúdo, por meio de exaustivo contato com o material, para constituir o corpus e formular algumas hipóteses de trabalho. Escolhem-se os documentos a serem analisados, alinhados aos objetivos iniciais da pesquisa para elaborar indicadores de interpretação final do texto. A etapa seguinte é a exploração do material, que consiste em separar as categorias ou eixos temáticos, a serem discutidos adiante. É a transformação dos dados brutos em dados possíveis de compreensão textual. A terceira etapa, tratamento do material, destina-se à análise e interpretação dos resultados. Dessa forma, serão abordados os temas predominantes nas falas dos participantes e analisados com base na literatura consultada.

\section{RESULTADOS}

A. Caracterização das avós:

Iniciaremos apresentando os dados sociodemográficos e as condições que levaram à criação dos netos.

\section{Avó Safira}

Tem 64 anos de idade, católica, vive em união estável com o seu companheiro, que se mostrou bastante cúmplice da participante, inclusive, esteve ao seu lado no decorrer da entrevista e demonstrou ser um avô socioafetivo muito presente na vida do menino. Ela teve onze filhos, estudou até a $4^{a}$ série do ensino fundamental, mas não teve condições de continuar estudando, pois trabalhava na roça quando criança. Hoje não possui trabalho formal, mas já trabalhou como doméstica, em casas de família. Mora com o companheiro e o neto, em uma residência modesta. Possuem uma renda de um salário mínimo referente à aposentadoria do neto, que é deficiente físico e mental, além do valor dos "bicos" do esposo, como servente. Alegou que todo o dinheiro da aposentadoria da criança é utilizado para as suas despesas, que são muitas, já que ele precisa ser assistido por especialistas e faz uso de vários medicamentos. Esse neto é filho de sua falecida filha, que sofreu um acidente de moto e veio a óbito em decorrência da batida. A criança morava em sua casa desde o nascimento, já que a mãe também residia na mesma moradia. 
A avó mostrou ser uma mulher humilde, calma, fala baixo e nutre um forte amor pelo neto. Demonstrou ter uma atitude positiva frente às dificuldades da vida, verbalizando com entusiasmo a forma como cuida do neto e como ele sempre está bem apresentado. Ela se emocionou ao recordar da filha falecida, mas sente-se conformada por saber que está cuidando do neto com zelo e carinho. O casal pareceu ser bastante unido, sempre mostrando fotos da criança durante a entrevista.

\section{Avó Esmeralda}

Tem 49 anos de idade, católica, casada há 30 anos. Estudou até a $3^{a}$ série do ensino fundamental, pois a mãe adoeceu e ela precisou assumir a casa, tralhando como doméstica em casa de família. Teve cinco filhos e tem seis netos. Possui, na frente de sua residência, uma barraquinha onde vende lanches, o que ajuda na renda da família. O esposo está desempregado e faz trabalhos de pedreiro, recebendo pouco mais que um salário mínimo.

Em sua casa, além dela, moram o esposo, os dois netos e um filho adolescente. Seus dois netos moram em sua residência desde o nascimento e ela passou a ser a responsável por eles após o assassinato do filho. A mãe das crianças é viva, porém não possui vínculo afetivo com as crianças.

\section{Avó Ametista}

Tem 42 anos de idade, evangélica, casada há 30 anos, estudou até a $4^{a}$ série do ensino fundamental, do lar. Teve um único filho, pai da neta que ela cuida. Seu filho tem duas filhas: a filha mais velha, que é a neta que mora com ela, e a mais nova que mora com o pai, o qual constituiu uma nova família. A residência da avó é uma casa de herdeiros, que foi dividida em outras casas onde moram o seu pai e sua irmã. Em sua casa moram ela, o esposo e neta. A renda da família é $\mathrm{R} \$ 1.200,00$ decorrente ao trabalho de serviços gerais do esposo, em um edifício.

A neta vive sob seus cuidados desde o nascimento, já que a genitora também morava junto com seu filho. Contudo, ela foi embora sem explicações e abandonou a filha. A avó alegou que gosta da genitora da sua neta, contudo não aprova suas atitudes pessoais, pois ela tem uma companheira, e acha que isso pode interferir de forma negativa na vida da neta, que já vem se mostrando constrangida com essa situação. O seu filho, pai da criança, mantem contato com a filha, visitando-a sistematicamente, já a mãe não a vê há anos.

\section{Avó Turmalina}

Tem 63 anos, viúva há seis meses, tendo vivido por trinta anos com o companheiro. Teve quatro filhos, sendo que o seu marido entregou um deles para outra família cuidar. Estudou até a $4^{a}$ série do ensino fundamental. Hoje, não está trabalhando, mas já trabalhou como cuidadora de idosos, em hospitais. 
A renda da família é constituída por dois salários mínimos (benefício de prestação continuada de um filho, portador de necessidades especiais, e pensão do esposo falecido).

Na sua casa moram ela, dois filhos, um deles doente mental, e dois netos. Tem apenas a guarda de um dos netos, apesar de cuidar dos dois. Ambos são filhos do mesmo pai, que está preso, há oito anos. No decorrer da entrevista, ela demonstrou a sua insatisfação e desgosto por ter que cuidar dos dois netos, principalmente na idade atual, porque está cansada e gostaria de viver a sua vida de forma mais tranquila.

Ela informou que não mantinha contato com os netos e que foi uma surpresa quando eles chegaram à sua residência, acompanhados de seu filho, que vivia no interior. $O$ pai das crianças as abandonou sob seus cuidados, "tendo caído no mundo" e aparecido preso, acusado de homicídio. A mãe havia morrido no parto e as duas crianças, que não conheciam a avó paterna, foram morar com ela, mesmo sem ser seu desejo. Inclusive, quando recebeu os netos para morarem em sua residência, o seu esposo, que também vivia na mesma moradia, foi contra a permanência das crianças, o que acarretou sérios conflitos na convivência familiar. Ela se considera uma pessoa comunicativa, sincera, honesta, mas encontra-se bastante desgostosa perante a vida. Está aguardando a saída do filho do presídio para devolver as crianças ao pai.

5. Avó Rubi

Tem 60 anos de idade, católica, viúva, com renda de um salário mínimo, referente a aposentadoria. Teve dez filhos e hoje cuida de três netos. Mora em uma casa ampla, com seus três netos e alguns cachorros. Seu filho, pais dos netos que ela cuida, faleceu após um acidente de moto que vitimou este rapaz e mais duas pessoas que estavam em outra moto. A partir disso, ela passou a cuidar dos netos, já que a mãe das crianças não tinha condições financeiras e emocionais para ser a responsável por elas. Eles passavam o dia em sua casa e, com o passar do tempo, foram ficando até a efetivação da guarda. Mostrou-se muito falante, alegre, brincalhona e procura levar a vida de forma leve, buscando enxergar o lado positivo dos obstáculos que porventura surgem.

B - Dando voz às avós: resultados das entrevistas

Nesta seção iremos nos deter nas categorias que emergiram para analisar as informações obtidas, que foram quatro: sentimentos experimentados por criar os netos; chegada à Justiça; ganhos decorrentes da obtenção da guarda; lugar ocupado pelas avós.

Sentimentos experimentados por criar os netos

Nos relatos das avós foram percebidos sentimentos diversos, que vão desde uma felicidade exagerada a um mal-estar permeado de sofrimento. 
Entretanto, de um modo geral, foi possível notar que prevaleceu o sentimento de alegria e satisfação na convivência com os netos, conforme as seguintes falas:

[...] Sentimento de felicidade, graças a Deus. Todo mundo diz que vou ter muita vitória pela frente por isso. E eu faço as coisas com boa vontade, não faço com má vontade. Compro as coisas com boa vontade para ele, tenho aquele prazer, aquela alegria. (Safira, 64 anos)

[...] Ela é o amor da minha vida. Foi uma alegria tão grande, minha filha. Foi muito bom, muito bom mesmo... Eu me sinto muito feliz. Não me arrependo de nada. Faço de tudo por ela. Gosto demais dela. Dou o que tenho e o que não tenho. (Ametista, 42 anos).

[...] Eu me sinto como se fosse um presente... É assim: a alegria da casa é eles dois. Aí eu me sinto feliz. Agora me sinto muito feliz, a alegria da minha casa é eles dois... (Esmeralda, 49 anos).

Para elas, por ser uma mulher, mãe e avó seria natural, também, ser a cuidadora do lar e dos membros da família. Nesse viés, a rigidez nas atribuições das atividades femininas, passada culturalmente de geração em geração, apresenta uma imagem naturalizada do papel de mulher/mãe cuidadora e dedicada aos trabalhos da casa (Barros, 2013).

Apenas uma avó expressou um forte mal-estar, verbalizando o seu desagrado, desgosto e frustação por ter recebido a incumbência de cuidar do neto, mas, ainda assim, demonstrou conformidade com a situação, já que, apesar da sua situação "perturbada", ela se sente importante e útil na vida do neto, como pode ser observado na frase a seguir: "[...] Eu sou muito perturbada. Perturbada porque tem eles dois, e tem os outros dois filhos, tudo dentro de casa, né ? Aí é nesse sufoco assim... Não queria aceitar, mas era um caso de urgência." (Turmalina, 63 anos).

As falas da Turmalina expressaram tristeza e desgosto em relação ao fato de ter que se responsabilizar pelos netos. Ela verbalizou que a permanência dos netos em sua residência não foi uma escolha, uma vez que a mãe das crianças é falecida e o filho está recluso no presídio, não havendo outros familiares disponíveis a recebê-los. Pudemos perceber o sentimento de inconformidade desta avó, conforme as frases a seguir:

[...] Vou dizer uma coisa a você.. Desde o tempo que eu tomei conta dessas criaturas que eu não tive mais sossego. [...] Eu pensei que ser avó era só ser avó e pronto. Não chegar ao ponto de tomar conta, pegar uma reponsabilidade como eu peguei deles. [...] Ser avó era para ser apenas avó, sem a responsabilidade de cuidar dos netos. (Turmalina, 63 anos).

Essa última frase corrobora com a reflexão que foi trazida por Dias (1994) no sentido de que o ideal seria que os avós não precisassem mais se desgastar com as tarefas rotineiras de assistência, criação e educação dos netos. Em outro texto, Dias, Aguiar e Hora (2009) apontaram para o fato de que ter avós como cuidadores pode ser benéfico para as crianças, principalmente porque poderão 
usufruir de uma sensação de pertencimento à sua família de origem, especialmente na ausência dos pais. Entretanto, é preciso estar atento para as possíveis complicações emocionais que podem surgir nas avós, advindas desta situação.

Dias (2015) ressaltou que existem posições distintas quanto à criação dos netos, por parte dos avós. Enquanto alguns aceitam criar os netos por obrigação ou responsabilidade, outros o fazem com prazer e alegria. Porém, foi possível observar a presença de sentimentos ambivalentes, onde coexistem afeto aos netos e ressentimento contra os filhos por terem-nas deixado nessa situação. Existe ainda o sentimento de perda por não estarem convivendo com os/as companheiros/as de sua idade ou realizando projetos antigos, ou até mesmo, simplesmente descansando. Acrescenta-se a isto, preocupações quanto ao cuidado e ao futuro dos netos.

Uma avó apresentou claramente sentimentos ambivalentes:

[...] É verdade que é uma responsabilidade muito grande, mas apesar dessa responsabilidade, para mim, é como se Jesus tivesse me presentado com eles dois; é uma responsabilidade, mas é uma alegria. [...] Eu dizia sempre assim: eu quero ser avó, mas não quero cuidar de neto. Porque eu já tinha cuidado de cinco filhos, já tinha ajudado a minha irmã a cuidar dos outros irmãos da gente, né? Mas assim... Deus me deu essa oportunidade, né, porque por mim mesmo, eles estavam com a mãe e eu ajudando ela, mas sendo que ela não quis, entendeu? Mas para mim é uma alegria muito grande, é um presente. (Esmeralda, 49 anos).

A ambivalência de sentimentos também foi registrada por Peixoto e Luz (2007), ao comentarem que as relações familiares não são apenas conduzidas pela harmonia das relações de troca entre gerações, mas também por sentimentos contraditórios de amor e ódio, bondade e avareza, solicitude e descaso que coexistem entre os membros da família.

\section{Chegada à Justiça}

Foram percebidos vários motivos pelos quais as avós procuraram a Justiça para solicitar a guarda dos netos. As razões foram desde óbito de um dos genitores, envolvimento com drogas, reclusão em presidio ou a regularização de uma situação fática existente. Entretanto, os motivos predominantes foram falecimento do genitor e o abandono materno. Os relatos das avós corroboram com a reflexão de Dias (2015) quando aponta para o fato de que os avós passaram a se responsabilizar integralmente pela criação dos netos, devido a fatores como gravidez na adolescência, envolvimento com drogas, imaturidade, negligência, doenças ou morte dos pais, como pode ser visto nas falas a seguir: "[...] O pai morreu, a mãe desapareceu. Eu precisei da guarda para andar com ele." (Safira, 64 anos).

[...] Ela foi embora, tava desaparecida. Aí foi quando procurei o Conselho Tutelar, contei o que estava acontecendo... Aí eles tentaram entrar em contato com ela, não conseguiram. Aí foi quando eles 
mandaram eu ir para DPCA... Mas eu fui para Justiça e eu fui orientada a pegar a guarda. (Esmeralda, 49 anos).

A maior parte das avós entrevistadas já cuidava dos netos desde o nascimento, pois um dos genitores também vivia na mesma residência com os avós e por razão de óbito, desaparecimento ou prisão, elas passaram a ser cuidadoras em tempo integral de seus netos, muitas vezes sem nenhum tipo de auxílio dos pais biológicos. "[...] Ajudava em nada não, ele sumiu, minha filha... sumiu... até chegar ao ponto de cair onde caiu. Apareceu, estava preso..." (Turmalina, 63 anos).

Esses achados confirmam o que foi encontrado na pesquisa de Mainetti e Wanderbroocke (2013) no sentido de que o cuidar dos netos em tempo integral, pelas avós, apenas consolidou uma situação que já vinha ocorrendo.

De acordo com Lima e Rocha (2014), a função parental assumida pelos avós pode ocorrer de forma jurídica ou informal, e a segunda pode trazer prejuízos à criança, quando, por exemplo, ela precisa ser matriculada em alguma instituição de ensino, ter acesso a tratamento em hospitais, entre outros, que exijam a autorização de um responsável legal. Nesses casos, é preciso comprovar a custódia legal do menor, e quando os avós assumem a responsabilidade parental, por meios legais, são nomeados avós com custódia. Existem avós que cuidam de seus netos, desde o nascimento, e, muitas vezes, não têm conhecimento de que precisam ter a guarda legal dos mesmos pelo fato de já possuírem laços sanguíneos. Na Justiça, é comum ouvir que, por serem avós, eles acham que estão livres de uma ação judicial. Por esta razão, apenas quando acontece algo mais sério com os genitores, como morte ou ausência extrema, é que procuram ajuda para poderem se resguardar juridicamente.

[...] Ela (genitora) estava desaparecida, ninguém sabia onde ela estava. A família sabia né, mas dizia que não sabia. Eu disse que não queria pegar a guarda... Aí me disseram: 'Mas se a senhora não quiser e a família dela também não quiser, eles vão para adoção'. Aí quando falou em adoção eu não ia deixar, né? Não ia deixar meus netos irem para adoção. Aí peguei a guarda provisória e depois fiquei de vez. (Esmeralda, 49 anos)

[...] É porque teve a parte da família dele lá, parte do pai... A gente ficou sem saber .... com medo... Fiquei com medo de eles quererem tomar o menino também, né... aí com a guarda não podia. (Safira, 64 anos)

[...] Ela foi embora e deixou a filha... Aí eu disse, sabe de uma coisa, eu vou procurar meus direitos. Porque eu não sabia o que passava na cabeça dela, né? Ela se separou do meu filho assim... Sem ninguém entender... Fiquei com medo... O motivo de ir para a Justiça foi o medo da mãe dela levar. Era medo. Medo. Eu tenho até hoje, medo... porque ela é mãe, né..? Mesmo tendo abandonado. (Ametista, 42 anos)

[...] A gente tem medo, né... a gente fica cuidando direito das crianças, passa anos se esforçando, depois chega alguém e aparece 
querendo levar os meninos... A gente tem medo e não vai deixar. (Rubi, 60 anos)

\section{Ganhos decorrentes da obtenção da Guarda}

Nesta categoria, todas as participantes declararam ter adquirido benefícios a partir da obtenção do termo de guarda na Justiça. Três das cinco avós expressaram com satisfação que, com o documento legal, se sentiram amparadas juridicamente, asseguradas diante de uma possível retirada da criança de sua convivência, já que o maior receio delas seria perder o papel de cuidadora dos netos:

[...] Para mim facilitou, facilitou muito, muito mesmo. Para mim eu achei bom em estar com esse documento na minha mão porque isso aqui é uma prova. (Safira, 64 anos).

[...] Não corre o risco da outra família querer pegar ele. (Safira, 64 anos).

[...] Ponto positivo porque assim né, eu estou acobertada pela Justiça. (Esmeralda, 49 anos).

[...] O ponto positivo: tudo. Principalmente a segurança, eu tenho segurança. Antes eu tava com as mãos atadas. A qualquer momento alguém poderia levar. Mesmo com o pai presente, podia ser que a mãe viesse e o juiz desse o direito à mãe, porque mãe é mãe. Aí meu medo era esse. Eu sempre tive medo de tirarem Clara de mim. Primeiramente Deus e segundo o papel da guarda. (Ametista, 42 anos).

Vale ressaltar que mesmo a avó Turmalina, que no decorrer de toda a entrevista alegou a sua insatisfação, cansaço e desgosto por ter assumido o neto, ainda assim percebeu que foi um ganho em sua vida ter adquirido o termo de guarda, porque, desta forma, pôde matricular o menino em uma Instituição de Ensino e deixá-lo munido dos documentos necessários à sua cidadania, além de acolhê-lo, num momento em que ele não possuía mais nenhuma referência: "[...] Eu não tinha percebido nenhum ponto positivo não, mas olhando assim foi positivo para ele poder estudar, tem os documentos, é foi bom sim... Ele não tinha mais ninguém, tinha a mim." (Turmalina, 63 anos).

Nesse sentido, Lopes, Neri e Park (2005) citaram como benéfico para as crianças terem seus avós como cuidadores, porque, na ausência dos pais, poderão ter uma sensação de pertencimento à sua família de origem.

Uma das avós comentou que, a partir da obtenção da guarda, a sua família se uniu ainda mais, principalmente no tocante à sua relação com o seu esposo. O ponto mais forte da obtenção da guarda, para ela, foi uma maior união familiar.

[...] Mudou a minha convivência com o meu esposo, a gente se uniu mais né, que a gente viu que era uma responsabilidade muito grande, duas crianças pequenas dentro de casa... Eu vi a alegria dos meus filhos com eles ali, tudo pequenininho... a união dos meus filhos ali... E eles me ajudando a cuidar deles. A família estava sempre junto. (Esmeralda, 49 anos). 
Assumindo novas funções e incorporando novos integrantes à sua família, concordamos com Lima e Rocha (2014) que os avós podem sentir essa situação de forma benéfica (maior autoestima, felicidade por realizar um importante papel para o neto não permitindo que saia do seio da família, entre outros) ou maléfica (dificuldade econômica, estresse mental e físico, cansaço, entre outros).

\section{Lugar ocupado pelas avós na família e sociedade}

Nesta categoria, independentemente dos sentimentos experienciados, dificuldades encontradas, conflitos ou benefícios vivenciados na família, bem como a satisfação e prazer em criar os netos ou ressentimento e mágoa por esta situação, as participantes declararam, unanimemente, ocupar o lugar de mãe de seus netos.

Paula, Silva, Bessa, Morais e Marques (2011) ressaltaram que, para as avós, ao se colocarem no lugar das filhas ou das noras, pode haver uma possível a recuperação do papel de mãe, o que torna este fato cheio de significados. Desta forma, cuidar de um neto pode proporcionar-lhes a sensação de terem cumprido todas as etapas de sua vida na família e na sociedade e ainda estarem em condições de auxiliar seus filhos a criar e educar sua prole.

Elas se perceberam em uma posição que deveria ser ocupada pela mãe biológica, e se sentem reconhecidas, inclusive pelos demais familiares, como sendo a mãe das crianças. Não só elas se percebem neste lugar, como também os parentes, vizinhos e os próprios netos. Lopes, Nery e Park (2005) afirmaram que os avós tiveram seus papéis ampliados, sendo cada vez mais comum ter netos morando consigo, onde os avós lhes oferecem cuidados diários, responsabilizando-se de forma material e afetiva, inclusive obtendo a sua guarda legal.

[...] Eu me vejo como mãe dela. [...] Meu lugar é de mãe dela; [...] Para meu marido ele se vê como pai de Clara, eu mãe e ele pai. Os outros familiares também veem assim. Os outros acham que eu tenho esse lugar de mãe, os vizinhos também me veem assim. (Ametista, 42 anos).

[...] Eu acho que meu lugar na vida deles é como se fosse uma avó que eles podem se espelhar como uma mãe. É uma avó mãe. Eu me acho importante... O meu lugar ali é como se eu fosse uma rainha na minha casa, ali tudo é comigo. [...] Eles me chamavam de mãe, mas eu não quis, porque eu queria ser chamada de avó, né, era meu sonho ser avó... Mas eles ficam me chamando de mãe e eu deixo (Esmeralda, 49 anos).

[...] Na família, eu me sinto como se fosse a mãe dele, é. Eu me sinto... porque tenho aquele prazer de cuidar, como cuidei de todos os meus filhos... O lugar que eu ocupo é de mãe mesmo. (Safira, 64 anos).

[...] Tudo o que faço por eles é o que a mãe deveria fazer... .Meu lugar é o lugar de mãe... eu sou a mãe deles. (Rubi, 60 anos). 
[...] Eles (referindo-se ao neto com guarda legal e ao neto sem guarda legal) ocupam um lugar de filho, né mulher?... Eu ocupo o lugar de uma mãe, porque sou avó e mãe, bem dizer..; [...] $\mathrm{O}$ restante da família me vê assim também, como uma mãe. (Turmalina, 63 anos).

Goldfarb e Lopes (2006) pontuaram que, com os novos arranjos familiares, os limites e as fronteiras tornaram-se expandidos e difusos, levando os avós a assumir ou sobrepor papéis diante da ausência parental. As autoras ressaltaram que ainda que os avós desempenhem o papel parental, os filhos, agora pais, não deixarão de ser pais/mães porque a função foi transferida. Entretanto, o lugar e a função dos avós podem se confundir com os dos verdadeiros depositários desses papéis, em virtude dos desafios sociais e econômicos que a família enfrenta na contemporaneidade.

Chamou a atenção a fala de uma avó que se referiu à substituição do filho falecido pelos netos: "[...] Com a perca do meu filho, eu botei eles dois no lugar do meu filho... por causa deles eu não caí na depressão, foi um presente de Deus para mim." (Esmeralda, 49 anos).

Destacamos ainda um trecho da entrevista de uma avó que atribuiu o sentimento de ser avó a uma reavaliação de seu papel como mãe, procurando fazer melhor agora: "[...] É ser uma mãe, e o que é melhor é que posso fazer diferente em alguns momentos né, ser diferente e até melhor do que era com a mãe dela." (Rubi, 60 anos).

De acordo com Barros (1987), a condição de se tornar avós estimula a lembrança das próprias experiências anteriores de criação dos filhos. Essas lembranças podem ser importantes na revisão e aceitação da própria vida, assim como de qualquer desapontamento ou fracasso. Neste sentido, o desempenho do papel de avó/avô vai permitir uma reflexão acerca da própria infância e do seu papel enquanto pais e, assim, a relação entre avós e netos acontece em um espaço de encontro entre vários papéis e gerações (Newman \& Newman, 2012; Sousa, 2006).

\section{CONSIDERAÇÕES FINAIS}

Um dado que emergiu nesta pesquisa e que merece ser tratado é que a maioria das avós é de vinculação paterna. Das cinco participantes, apenas uma é avó materna, o que destoa um pouco do que geralmente é encontrado na literatura, em que se observa uma prevalência de avós maternas assumindo os cuidados dos netos, na falta ou impossibilidade dos genitores em se responsabilizar pelos seus filhos (Dias, 2015). Esse achado pode sugerir que os pais, nos dias atuais, estão mais presentes na vida de seus filhos, o que, consequentemente, acarreta o maior envolvimento da família paterna (FéresCarneiro, Ziviani, Magalhães, \& Ponciano, 2013). Em um dos casos, a genitora abandonou a filha para morar em outro estado e o pai permaneceu na cidade de 
origem e, apesar de não ser o responsável legal da filha, ele é presente e participativo em seu cotidiano, contribuindo nos cuidados e dando suporte à avó paterna, que passou a ocupar o lugar de mãe. A esse dado se soma que a maioria das mães deixou os filhos aos cuidados dos avós, não mantendo relação com eles, enquanto duas delas faleceram.

A diversidade de arranjos familiares na atualidade dá espaço para relações baseadas em laços afetivos e não somente em laços consanguíneos. Isso pode ser notado quando o companheiro de uma das participantes se autodenominou como avô da criança, demonstrando forte relação afetiva com o neto, sendo presente e bastante ativo em seus cuidados.

Verificou-se que, para as avós, a função materna se sobrepôs ao papel de avó. Apesar disso, constatamos a naturalidade com que assumiram esse lugar, com exceção de uma avó que se mostrou muito sobrecarregada por criar dois netos. As figuras de pai e mãe são reconhecidas na vida das crianças, contudo, em sua maioria, não são presentes, e, por essa razão, as avós assumiram o lugar desses genitores em sua integralidade.

Apesar do afeto, cuidado, carinho e satisfação demonstrados na convivência com os netos, nos relatos das avós pode-se perceber a existência de ambivalência afetiva, por estarem no lugar parental e deixar de ser "simplesmente avós". Esse lugar acarreta uma sobrecarga física e emocional que leva a esses sentimentos conflitantes, em que as avós procuram balancear a satisfação de conviver com os netos com as dificuldades enfrentadas ao assumirem as responsabilidades perante eles.

Sugere-se que outras pesquisas sejam realizadas no tocante a essa questão da guarda, sobretudo quando os netos atingem a adolescência e passam a não querer atender aos limites impostos pelos avós (Dias, Aguiar, \& Hora, 2009). Trata-se de situações delicadas e que precisam ser investigadas. Reconhece-se também a necessidade de orientação e escuta a essas avós.

Espera-se que a discussão dos resultados desta pesquisa tenha contribuído com a literatura nas áreas da Psicologia e do Direito, como também com os temas do desenvolvimento humano e do envelhecimento, favorecendo um maior entendimento sobre a questão da guarda para os demais profissionais que lidam com essa temática.

\section{DECLARAÇÃO DE CONFLITOS DE INTERESSE}

Não há conflitos de interesse.

\section{REFERÊNCIAS}

Aratangy, L. \& Posternack, L. (2005). Livro dos avós, na casa dos avós é sempre domingo? São Paulo: Artemeios. 
Barros, M. M. L. B. (1987). Autoridade e afeto: avós, filhos e netos na família brasileira. Rio de Janeiro: Jorge Zahar Ed.

Barros, M. M. L. B. (2013). Transmissão de valores na família e conflitos intergeracionais: experiências femininas. Cadernos Adenauer, 14(3),125140.

Cardoso, A. R. (2011). Avós no século XXI: mutações e rearranjos na família contemporânea. Curitiba: Juruá.

Chaves, S. L. (2014). Para além da representação: A interface da guarda legal com o avocentrismo e as políticas sociais. Dissertação (Mestrado em Serviço Social) Universidade Federal de Pernambuco. Recife, Pernambuco.

Dias, C. M. S. B. \& Schuler, E. (2013). Uma proposta de intervenção psicoeducativa com avós que criam seus netos. In A. Garcia, \& R. DíazLoving (Orgs), Relações familiares: estudos latino-americanos (pp 30-43). Vitória: UFES.

Dias, C. M. S. B. (1994). A importância dos avós no contexto familiar. Revista Psicologia Teoria e Pesquisa, 10(1), 31-40.

Dias, C. M. S. B. (2015). As relações intergeracionais na família: desafios e possibilidades. In: T. Féres-Carneiro (Org.), Família e casal: parentalidade e filiação em diferentes contextos (pp. 93-102). Rio de Janeiro. Ed. PUC- Rio: Prospectiva.

Dias, C. M. S. B., Aguiar, A. G. S. \& Hora, F. F. A. (2009). Netos criados por avós: motivos e repercussões. In: Féres-Carneiro, T. (Org.). Família e casal: permanências e rupturas (pp. 41-58). São Paulo. Casa do Psicólogo.

Dias, C. M. S. B., Costa, J. M \& Rangel, V. A. A. (2005). Avós que criam seus netos: circunstâncias e consequências, In T. Féres-Carneiro (Org.), Família e casal: efeitos da contemporaneidade (pp. 158-176). Rio de Janeiro: PUC/Rio.

Dias, C. M. S. B., Fonseca, C. M. S. M. S., Silva, C. F. S \& Muniz, F. M. R. P. (2013). Uma Intervenção psicoeducativa com avós guardiãs apresentando ansiedade e/ ou depressão. In T. Féres-Carneiro (Org.), Casal e família: transmissão, conflito e violência (pp. 53-72). São Paulo: Casa do Psicólogo.

Dolto, F. (1998). Os caminhos da educação. São Paulo: Martins Fontes.

Féres-Carneiro, T., Ziviani, C., Magalhães, A. S. \& Ponciano, E. L. T. (2013). Ser pai (mãe), ser filho(a): a resolução de conflitos em famílias contemporâneas casadas. In T. Féres-Carneiro (Org.), Casal e Família: transmissão, conflito e violência (pp. 73-98). São Paulo: Casa do Psicólogo.

Goldfarb, D. C \& Lopes, R. G. C. (2006). Avosidade, a família e a transmissão psíquica entre gerações. In E. V. Freitas et al., Tratado de Geriatria e Gerontologia (pp. 1374-1382). (2a ed.) Rio de Janeiro: Guanabara Koogan. Lei $n^{\circ}$ 8069, de de 13 de julho de 1990. Dispõe sobre o Estatuto da Criança e do Adolescente e dá outras providências. Recuperado de http://www.planalto.gov.br/ccivil_03/leis//8069.htm. 
Lima, C.A.S. \& Rocha, A.J. (2014). O processo de reparação na mudança da avosidade para a parentalidade baseado na custódia e educação dos netos. Revista Educação, 9(1), 61-83.

Lima, H.G.D. \& Ribeiro, R. (2008). Contribuições da psicologia jurídica na prática psicossocial na Justiça. In E. F. Bastos \& L. Fernandes (Org.), Família e Jurisdição II (pp. 143-162). Belo Horizonte: Del Rey.

Lopes, E. S. L., Neri, A. L. \& Park, M. B. (2005). Ser avós ou ser pais: Os papéis dos avós na sociedade contemporânea. Textos sobre Envelhecimento, 8(2), 30-32.

Mainetti, A. C.\& Wanderbroocke, A. C. N. S. (2013). Avós que assumem a criação dos netos. Pensando Famílias, 17(1), 87-98.

Minayo, M.C.S. (2014). O desafio do conhecimento: pesquisa qualitativa em saúde. (14a ed). São Paulo: Hucitec.

Minuchin, S. (1990). Famílias: funcionamento \& tratamento. Porto Alegre: Artes Médicas.

Newman, B. M. \& Newman, P.R. (2012). Development through life: A phychossocial approach. Wadswort: Cengage Learning, 2012. Recuperado em 15 de junho de 2017, de https://books.google.com.br/books?id=oTY_7osGmqUC\&printsec $=$ frontcove $r \& h l=p t-B R \&$ source $=g b s \_g e \_s u m m a r y \_r \& c a d=0 \# v=$ onepage \&q\&f=false

Osório. L. C. (2013). Como trabalhar com sistemas humanos. Porto Alegre: Artmed.

Paula, F.V., Silva, M. J., Bessa, M.E.P., Morais, G.L.A. \& Marques, M. B., (2011). Avós e netos no século XXI: autoridade, afeto e medo. Revista Rene, 12(Número especial), 913-921.

Pedro, J. G. (2006). O papel dos avós no século XXI. Revista Povos e Culturas. Os avós como educadores, 10, 11-24. Lisboa: CEPCEP.

Peixoto, C. \& Luz, G. M. (2007). De uma morada a outra: processo de recoabitação entre as gerações. Cadernos Pagu, 29, 171-191. Recuperado em 30 março 2016, de http://www.scielo.br/pdf/cpa/n29/a08n29.pdf.

Rocha, S. M. S. (2017). Um estudo sobre as demandas judiciais dos avós nas varas de família. Dissertação (Mestrado em Psicologia Clínica), Universidade Católica de Pernambuco, Recife.

Schuler, F. M. G. \& Dias, C. M. S. B. (2017). Maternal migration: a study on the children who have stayed. International Review of Couple and Family Psychoanalysis, 17, 1-13.

Sousa, L. (2006). Avós e netos: Uma relação afetiva, uma relação de afetos. Revista Povos e Culturas. Os avós como educadores, 10, 39-50. Lisboa: CEPCEP.

Vasconcellos, M. J. E. (2002). Pensamento sistêmico: o novo paradigma da ciência. Campinas: Papirus. 
Vitale, M. A. F. (2008). Avós: velhas e novas figuras da família contemporânea. In A. R. Acosta \& A. F. Vitale (Eds.), Família, redes, laços e políticas públicas (pp. 93-105). 4a ed. PUC/ São Paulo: Cortez.

Walsh, F. (2016). Processos normativos da família, diversidade e complexidade. $4^{\mathrm{a}}$ ed. Porto Alegre: Artmed.

Sobre as autoras

Cristina Maria de Souza Brito Dias é psicóloga, possui Mestrado e Doutorado em Psicologia pela UNB, especialização em Terapia Familiar e de Casal. Professora Adjunta IV aposentada da Universidade Federal da Paraíba. Atualmente é professora e pesquisadora na Universidade Católica de Pernambuco. Bolsista de produtividade do CNPq. E-mail: cristina.msbd@gmail.com.

Karlise Maranhão Lucena de Albuquerque é psicóloga pela Universidade Católica de Pernambuco, mestre em Psicologia Clínica pela Universidade Católica de Pernambuco. Trabalha no Judicial de Pernambuco na 1. Vara da Infância e Juventude. E-mail: karliselucena@hotmail.com.

Recebido em: 28/05/2019

Revisado em: 22/07/2019

Aceito em: 19/12/2019 